\title{
Targeting Carbohydrates and Polyphenols for a Healthy Microbiome and Healthy Weight
}

\author{
Matthias Van Hul ${ }^{1}$ • Patrice D. Cani ${ }^{1}$ \\ Published online: 3 June 2019 \\ (C) The Author(s) 2019
}

\begin{abstract}
Purpose of Review In this review, we focus on microbiota modulation using non-digestible carbohydrate and polyphenols (i.e., prebiotics) that have the potential to modulate body weight.

Recent Findings Prebiotics derived from plants have gained the interest of public and scientific communities as they may prevent diseases and help maintain health.

Summary Maintaining a healthy body weight is key to reducing the risk of developing chronic metabolic complications. However, the prevalence of obesity has increased to pandemic proportions and is now ranked globally in the top five risk factors for death. While diet and behavioral modification programs aiming to reduce weight gain and promote weight loss are effective in the short term, they remain insufficient over the long haul as compliance is often low and weight regain is very common. As a result, novel dietary strategies targeting the gut microbiota have been successful in decreasing obesity and metabolic disorders via different molecular mechanisms.
\end{abstract}

Keywords Obesity $\cdot$ Gut microbiota $\cdot$ Polyphenols $\cdot$ Dietary fibers $\cdot$ Prebiotics

\section{Introduction}

The prevalence of obesity continues to increase dramatically worldwide [1] and is considered a major threat to public health [2]. Obesity is associated with low-grade chronic inflammation, which contributes directly to detrimental health consequences such as metabolic disorders including cardiovascular diseases, liver steatosis, insulin resistance, and type 2 diabetes mellitus [3, 4]. The precise etiology of this obesity-related proinflammatory status remains to be fully elucidated, but dysfunction of the adipose tissue has long been regarded as the main culprit [5]. Today, it is generally accepted that changes in gut homeostasis could represent another potential source of inflammation. Indeed, over the last few years, the gut microbiome has been implicated in both beneficial and

This article is part of the Topical Collection on Diabetes and Obesity

Patrice D. Cani

patrice.cani@uclouvain.be

1 Université catholique de Louvain, WELBIO- Walloon Excellence in Life Sciences and BIOtechnology, Louvain Drug Research Institute, Metabolism and Nutrition Research Group, UCLouvain, Av. E. Mounier, 73 box B1.73.11, B-1200 Brussels, Belgium negative health outcomes in humans (for review [6]). The gut microbiota refers to the microbial community that resides in our intestinal tract. These inhabitants of the human body are separated in different phyla. Among them, the phyla Firmicutes, Bacteroidetes, and Actinobacteria represent approximately $90 \%$ of the microbiota, with the remaining portion belonging to the phyla Proteobacteria and Verrucomicrobia.

In 2006, a series of seminal papers led by Prof. Jeff Gordon and colleagues were the first to demonstrate a difference in the composition of the gut microbiota (i.e., a shift in the Firmicutes to Bacteroidetes ratio) and in the quantity of specific microbial metabolites such as shortchain fatty acids (SCFAs) between obese and lean humans or rodents $[7,8]$. Following these findings, different studies encouraged a better in-depth analysis of the microbiota at the taxonomical level (i.e., family, genus, and species). More recently, disturbances in diversity and composition of the gut microbiota have been associated with a wide variety of inflammation-related disorders and pathologies including metabolic disorders such as obesity and diabetes $[7,9]$, inflammatory bowel disease $[10,11]$, autoimmune diseases [12], allergy [13], and neurological disorders [14].

It is now becoming more and more clear that there exist many host-microbe interactions, mediated through the release 
of bioactive molecules by bacteria in the gut and absorption of these metabolites into the circulation. Two key groups of such metabolites are SCFA, from the fermentation of nondigestible carbohydrates, and the by-products of polyphenols.

\section{Carbohydrates}

\section{Carbohydrates, Fibers, and Health: A Brief History}

The impact of dietary fibers on health has been described over the last 40 years. Already in 1975, Trowell suggested that the etiology of type 2 diabetes could come from changes in the dietary habits and the lack of dietary fibers in the diet. It was also mentioned that the potential effect of sudden changes in dietary habits could partly explain the very high prevalence of diabetes observed in the Pima Indians. These hunter-gatherers shifted their classical diet - highly rich in non-digestible carbohydrates (i.e., fibers) - to a Western diet very low in fibers and cereal products [15]. In 1976, David Jenkins, another pioneer in this field, published a paper showing that the addition of non-digestible carbohydrates to the diet (i.e., guar and pectin fibers) "decreased markedly the rise in blood-glucose between 30 and 90 minutes also resulted in significantly lower insulin levels between 30 and 120 minutes" postprandially [16]. In these studies, the initial mechanism proposed was the "gel-forming" effect and the potential viscosity of the non-digestible carbohydrates. Indeed, pectin or guar gum may contribute to the so-called bulking effect (i.e., water retention), which was assumed to be the major mechanism explaining the effects observed [16-18]. Today, the positive association between non-digestible carbohydrates and health is undeniable and has been confirmed many times; however, it appears that their mechanisms of actions are more complex and cannot be explained merely by their bulking capacity.

\section{Non-digestible Carbohydrates and Microbiota-Derived Metabolites}

With growing insight into the role of non-digestible carbohydrates, it has become clear that their fate in the gastrointestinal tract is quite different than that of digestible carbohydrates, which are fully absorbed. Indeed, nondigestible carbohydrates escape the digestion that occurs in the first part of the gastrointestinal tract and find their way to the ileum and the colon, where they are digested by the gut microbes residing there.

This fermentation of carbohydrates in the lower parts of the gut is associated with the proliferation or the reduction of different bacteria but also with the production of several end products such as the SCFAs (e.g., acetate, butyrate and propionate) (Fig. 1). Although SCFAs have been studied in various situations and linked with gut health (for review [19-21]), it is worth nothing that those compounds can also reach the circulation and spread to different peripheric organs (e.g., the liver, the adipose tissue, the brain $[22,23])$. As a result, they have been implicated in the regulation of energy, glucose, and lipid homeostasis and they have also been closely associated with the regulation of immunity and cancer [19]. Thus, these microbial metabolites have abundant physiological effects.

\section{Non-digestible Carbohydrates, Microbes, and Body Weight Regulation}

The mechanisms explaining how fermented carbohydrate fibers improve metabolism have been initially revealed in rodents by using inulin-type fructans as prebiotics (e.g., inulin or oligofructose). We and others have contributed to the elucidation of the molecular mechanisms explaining how prebiotic feeding is associated with a decrease in body weight, fat mass gain, insulin resistance, and reduced food intake in rodents with genetic or diet-induced obesity [24-28]. Based on the reasoning of a potential impact of the microbial fermentation on a gut to brain axis, we discovered that fermentation of prebiotics leads to the modulation of gut peptides produced by the L-cells such as glucagon-like peptide-1 (GLP-1) and peptide YY (PYY), both involved in the regulation of appetite, body weight, and glucose metabolism [29]. Consequently, we found that the endogenous production of GLP-1 was increased (i.e., higher mRNA expression, peptide production and secretion, as well as an increase in the number of producing cells). Hence, the healthier phenotype was linked to greater GLP-1 and PYY levels in the portal vein blood [25-27]. Later, this finding was reproduced using resistant starches or arabinoxylans [30-33]. The molecular event explaining how fermentation increases gut peptides is generally attributed to the capacity of SCFAs to interact with specific G protein-coupled receptors such as GPR-43 (also referred to as FFAR2 for free fatty acid receptor 2) and GPR41 (also referred to as FFAR3) [34-36] (Fig. 1). Mice with deletion of these specific receptors are resistant to the beneficial effects of exposure to SCFAs or specific prebiotics and are characterized by an altered production of GLP-1 and PYY $[37,38,39 \bullet]$. Notably, in humans, we and others reported that modulation of the microbiome using prebiotics not only increased satiety and reduced hunger and appetite, but also increased the production of GLP-1 and PYY levels in both lean and obese volunteers [40-50] (for review [51]).

In 2018, a very interesting study was published by Liping Zhao and colleagues wherein they conducted a randomized clinical study that compared the impact of two isoenergetic diets that differed in their concentrations of prebiotics on the modulation of the microbiome [52••]. In this study, they performed an in-depth investigation of the mechanisms potentially explaining the beneficial effects of a diet rich in fibers; hence, they analyzed the composition of the gut microbiome (i.e., taxa and gene functions), the levels of plasma GLP-1 and 
Fig. 1 Non-digestible carbohydrates and polyphenols present in food can induce a shift in the microbial composition and favor beneficial bacteria like Akkermansia muciniphila. In addition, they can be fermented into short-chain fatty acids (SCFAs) or other metabolites that can either act locally, on epithelial cells and their receptors, or enter the blood circulation. SCFAs can activate receptors GPR41/43 and thereby increase GLP-1 and PYY hormone levels, while metabolites from polyphenols are able to activate AMPK in a broad range of tissues. Ultimately, both pathways result in the activation of cellular programs that favor the release of energy and promote energy expenditure

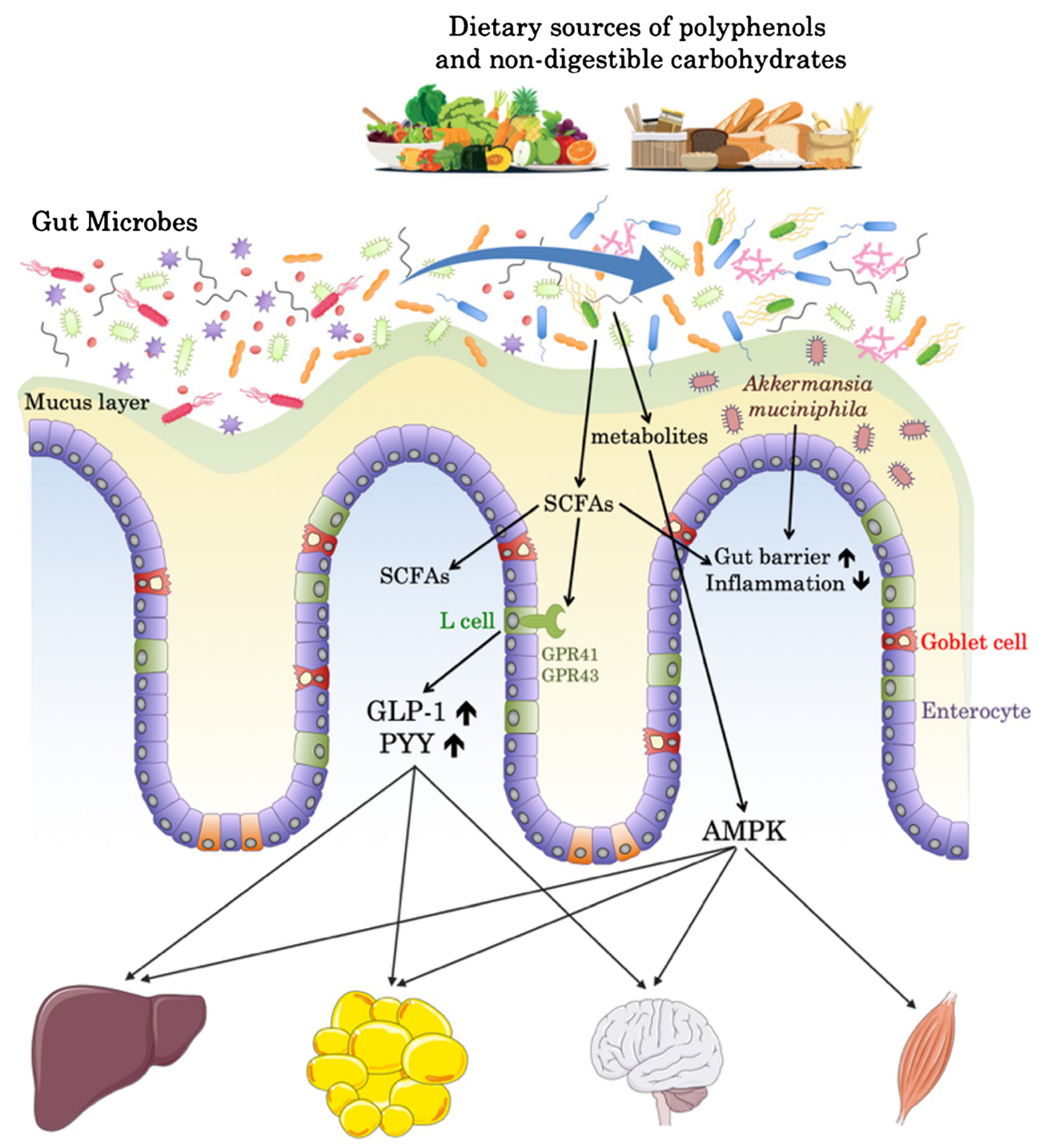

Glucose production $\downarrow$ Insulin sensitivity $\uparrow$
Food intake $\downarrow$ Energy expenditure $\uparrow$
Fat oxidation $\uparrow$ Glucose utilization $\uparrow$
PYY, and the measurements of SCFAs and other metabolites such as hydrogen sulfur and indoles. All subjects enrolled were diagnosed with type 2 diabetes and were treated with acarbose. At the completion of the study (i.e., 84 days), both groups exhibited a significantly lower level of hemoglobin $\mathrm{A} 1 \mathrm{c}(\mathrm{HbA1c})$; however, a greater reduction was observed in the group that received the high-fiber diet (composed of whole grains, traditional Chinese medicinal foods, and prebiotics) than in the control group, which received the usual care and was administered a diet that followed the normal dietary recommendations of the Chinese Diabetes Society. Only 50\% of subjects in the control group achieved adequate glycemic control (i.e., an $\mathrm{HbAlc}$ level $<7 \%$ ), whereas this goal was reached by $89 \%$ of the patients consuming the high-fiber diet. Similarly, the experimental group achieved greater reductions in body weight $(4.20 \pm 0.93 \%$ of body weight loss versus 1.45 $\pm 0.91 \%$ in the control group).
Since the microbial and metabolic profiles of both groups did not differ at the beginning of the study, the modulation of the gut microbiome by the fibers was likely to explain the phenotype. To causally link the different microbial and metabolic profile to the observed phenotype, the authors transplanted the gut microbiota from the participants into germ-free mice. Interestingly, when the mice were colonized with the gut microbiota collected after the dietary interventions, they displayed different metabolic improvements than mice that were colonized with the microbiota harvested before the intervention. However, the most interesting finding was that the mice colonized with the gut microbiota from the patients treated with the experimental diet also showed lower fasting and postprandial blood glucose levels than the control mice. It is worth noting that the beneficial effects were likely due to the combination of the different fermentable fibers and plants contained in the diet. Therefore, the synergistic effects 
observed are probably resulting from the impact on the microbiota of both, the sources of non-digestible carbohydrates and the different polyphenolic compounds (discussed in the next chapter of this review). These observations led the authors to conclude that the changes in the microbiome induced by increasing the consumption of non-digestible carbohydrates were sufficient to improve the metabolic parameters of patients with type 2 diabetes. Among the mechanisms, here again the levels of SCFAs correlated with improvements in several metabolic parameters, such as lower glycemia, blood lipid levels, and fat mass, as well as increased blood levels of GLP-1 and PYY [52••].

Although this study and other related studies have correlated the abundance of SCFAs and gut peptides with metabolic effects, researchers have not yet been able to completely ascertain whether the duo of SCFAs and gut hormones completely explain the observed results in humans.

\section{Polyphenols}

\section{Polyphenols and Health}

The first definition of prebiotics - a non-digestible food ingredient that beneficially affects the host by selectively stimulating the growth and/or activity of one or a limited number of bacteria in the colon, and thus improves host health [53] — was tailored to fibers. However, based on a fast-growing body of literature, this definition has continued to evolve over time [54], with the latest consensus being that a prebiotic is a substrate that is selectively utilized by host microorganisms conferring a health benefit, thus expanding the concept to also include non-carbohydrate substances [55••]. Indeed, some beneficial microbes also gain proliferating advantages from other compounds that are not covered by the initial description of a prebiotic. Polyphenols fall into this category.

Polyphenols constitute a large heterogenous family of over 8000 phytochemicals characterized by hydroxylated phenyl moieties [56]. They are classified based on their chemical structure and complexity (i.e., the number of phenolic rings and substituting groups), but generally they are broken down into two categories: flavonoids and non-flavonoids [57]. Nonflavonoids include phenolic acids, stilbenes, and lignans. Flavonoids are further divided into subclasses including flavanones, flavones, dihydroflavonols, flavonols, flavanols, anthocyanidins, isoflavones, and proanthocyanidins. Polyphenols are bioactive compounds that are second only to carbohydrates when it comes to abundancy in plants, where they have a protective role against, for example, damage from UV radiation and pathogens.

Although they have been used in traditional medicine for a long time, we are only now beginning to understand their mechanisms of action and accumulating literature is demonstrating that the consumption of polyphenol rich foods and beverages such as tea, coffee, fruits, vegetables, cereals, and wine could benefit human health. It is suggested that various polyphenols possess properties that could have preventive and/or therapeutic effects for cardiovascular diseases, neurodegenerative disorders, cancer, allergies, diabetes, and obesity [58-60].

\section{Polyphenols and Obesity}

There are several in vivo studies, both in animals and in humans that suggest a negative association between polyphenol intake and body weight $[58,60,61 \cdot 62-64,65 \bullet, 66]$. Perhaps the best-studied polyphenols in this context are the polyphenols from green tea $[67,68]$. Green tea is the dried leaves of Camellia sinensis plants. It contains the highest amounts of phenolic compounds and exhibits the highest antioxidant capabilities of any major tea type. It is rich in flavonoids (e.g., catechin, epicatechin, epicatechin gallate, epigallocatechin gallate, and proanthocyanidins). Of these, epigallocatechin gallate (EGCG) is considered the most significant active component. EGCG has been attributed antioxidant, anti-inflammatory and anti-mutagenic properties and is thought to help prevent weight gain [63, 67-70].

Besides (green) tea, many other sources of polyphenols have been studied for their potential preventive and therapeutic properties [63, 65 $]$. Coffee is rich in 3-caffeoylquinic acid, fruits such as blueberries have anthocyanins, red grapes and wine are a source of resveratrol, and spice like turmeric contains curcumin. All of these foods have been inversely associated with the metabolic syndrome and BMI in epidemiological studies [60].

It is important to note that some human epidemiological studies have shown inconsistent results. This may indicate that the benefits of polyphenols may depend on the method of administration or on the population studied $[63,65 \cdot]$. Also, the number of interventional studies providing direct evidence for these associations are still few, use relatively low doses of specific polyphenols, and occur over a short period of time [65•].

\section{Mechanisms of Action of Polyphenols}

How polyphenols exert their beneficial effects in the context of obesity is still a matter of debate. Polyphenols possess electron-donating phenolic groups in their structures, which allow them to locally prevent cellular damage caused by reactive oxygen species in the intestinal tract. However, although their antioxidant capacity is often cited, recent research suggests this is not the major cause for their effects on body fat accumulation [67]. A number of polyphenols have been shown to reduce nutrient intake in the gastrointestinal tract by interacting with and inhibiting digestive enzymes, thereby hampering starch, lipid, and protein digestion and absorption 
to reduce energy efficiency [71-76]. Other potential mechanisms of action include reduction of inflammation, modulation of glucose homeostasis, suppression of adipogenesis and lipid synthesis, increase of energy expenditure via thermogenesis, stimulation of fat oxidation, and excretion of fecal lipids $[60,61 \cdot, 62,77,78]$. The precise underlying molecular mechanisms, however, remain unclear. One possibility, the so-called "AMPK hypothesis" proposed by Yang et al., is that the polyphenols activate AMPK (adenosine monophosphate-activated protein kinase) $[61 \bullet 79]$. This "master switch" is ubiquitously expressed and serves as the master metabolic molecule that regulates how cells process energy, making it a heavily pursued target for treatment of metabolic diseases [80, 81]. Polyphenols have been shown in vivo and in vitro to activate AMPK.

\section{Polyphenols and Microbiota}

Most polyphenols, however, display poor bioavailability. They are not well absorbed in the small intestine [82] and are rapidly metabolized and excreted in urine and feces. However, when reaching the colon, they come in direct contact with the gut microbes, resulting in a complex and multidirectional interaction.

First, the antioxidant capacity of polyphenols ensures the protection of the colonic epithelial and mucosa architecture and shapes the environment in which gut microbes can thrive [83]. Second, since the vast majority of the polyphenols reach the colon almost unaltered, they are able to modify the intestinal microbiota, possibly affecting its capacity for energy harvest, and contributing to the improvement of health $[84,85]$. As a major source of nutrients for some microbes residing in the colon, polyphenols may also act as prebiotics and favor the growth of specific species [83, 86-91]. In addition, polyphenols may be involved in the adhesion of probiotic bacteria to the intestinal epithelia $[92,93]$. This could be important for their colonization and for their subsequent efficacy to exert physiological effects [94].

Third, polyphenols are subjected to catabolism by the microbiota and are degraded into low molecular weight bioactive compounds that are more easily absorbed through the intestinal barrier and are capable of exerting effects in peripheric organs [86, 95-98]. Perhaps the best known metabolites are the phenolic acids, to which several potential health benefits have been attributed, such as anti-microbial activities, antiinflammatory and anti-oxidative properties, reinforcement of the gut barrier, and also for regulating cyclooxygenase 2 activity [99•, 100]. Interestingly, it has been suggested that polyphenols may also be able to induce the production of SCFAs by colonic bacteria [67, 101-104]. This occurs either by the growth promotion of SCFA-producing bacteria (prebiotic effect), or by stimulation of their metabolic functions [105]. Finally, the intrinsic toxicity of the phenolic group gives polyphenols antibacterial activity [106-108]. As this may prevent biofilm formation and favor some bacterial species above others this feature allows polyphenols to further impact the microbial composition [109].

Although short-term animal studies clearly showed an effect of polyphenols on gut microbiota composition and obesity [110-114], it remains to be established whether these changes are significant enough to explain, at least in part, the health benefits of polyphenols in the long-term in human populations. For example, it has been described how the longterm supplementation of green tea did not change the gut microbiota in humans [115].

\section{Polyphenols and Akkermansia muciniphila}

Akkermansia muciniphila is a Gram-negative mucindegrading bacterium that, in contrast to most other gut microbes, resides within the mucus layer that covers the gut. It makes up $1-5 \%$ of the microbes in a healthy human gut, but its abundance is strongly reduced in the intestine of obese individuals. A. muciniphila is inversely associated with obesity, diabetes, cardiometabolic diseases, and low-grade inflammation, and the supplementation with $A$. muciniphila has been linked to beneficial effects in a variety of preclinical models [116-118].

In 2014, a study demonstrated that a polyphenol-rich cranberry extract prevented weight gain and ameliorated several features of the metabolic syndrome in diet-induced obese mice [111]. This was associated with a strong increase in the abundance of A. muciniphila in the gut microbiota. The exact mechanisms behind this increase are not known, but interestingly, it was shown that cranberry proanthocyanidins are also associated with an increase in the production of mucus, a major energy source for these mucin-degrading bacteria [119]. The increase in Akkermansia was later also observed in experiments that used extracts from grapes, that, like berries, contain abundant proanthocyanidins $[85,120]$, and also in studies using other types of berries and polyphenols [84, 121-124]. This suggests that polyphenols may exert at least part of their beneficial effects via a prebiotic effect on certain bacteria such as Akkermansia.

\section{Polyphenols as an Anti-obesity Drug}

The amplitude of the anti-obesity effects in humans will probably depend on many factors. Beside the classical interindividual variations (genetics and differences in gut microbiota composition), other factors such as how and when polyphenols are administered, may play a role. Since polyphenols and fibers share common plant-based sources, they are often consumed together. Interactions between polyphenols and polysaccharides are therefore inevitable. These interactions can have profound consequences on the extractability, 
bioavailability, functional characteristics, and on the fermentation kinetics of dietary fibers and/or polyphenols [125]. A study by Edwards et al. [126] aims at exploring this interplay and may lead to new product designs that further optimize the positive actions of dietary fibers and polyphenols. For example, because fibers are fermented, they may selectively increase the activity of specific bacteria which in turn may potentialize the presence of bacteria responsible for polyphenol catabolism. Moreover, polyphenols may also influence the fermentation of the fibers as numerous polyphenols exhibit both anti-microbial and prebiotic effects. Therefore, understanding the complex interaction between both dietary fibers and polyphenolic compounds will pave the way for designing future nutritional composition or food combination with an optimal health benefit [126].

Another critical factor is dosage. It is important to achieve high enough levels to have an effect, but overconsumption of polyphenols may not be without risk and caution is advised when preparing concentrated extracts [127, 128].

The anti-obesity effects of polyphenols may be further enhanced by habitual exercise $[129,130]$. In vitro data suggest that catechins inhibit the enzyme catechol-Omethyltransferase (COMT). This enzyme is partially responsible for the breakdown of norepinephrine, which is involved in the mobilization of fat from adipose tissues. If the lipids that are liberated are not maximally utilized by increasing physical activity, they will be stored again, attenuating the anti-obesity effects; however, whether this mechanism may explain the in vivo effects remains controversial [131].

\section{Conclusion}

While the obesity problem is often reduced to a simple mathematical imbalance between energy intake and energy expenditure, understanding how it develops and progresses is a complex problem that requires comprehension of multiple genetic, biologic, environmental, and socioeconomic factors. Countering its advance will require multidisciplinary and innovative approaches, combining dietary and behavioral changes with nutritional or therapeutic supplements, if needed. One of the components that can directly influence the outcome of such strategies is the gut microbiota. Indeed, the microbial community that colonizes the border between lumen of the gut and the inside of the body plays a decisive role in the host metabolism.

Non-digestible carbohydrates and polyphenols, two types of substrates that are metabolized by the gut microbes, represent an interesting set of tools to bend the microbiota to our advantage because they can modify the gut microbiota composition and be converted by the microbiota into useful metabolites. Which fibers or polyphenols will prove the most suited to maximize beneficial effects will probably depend on the specific situation and the individual (and its microbiota). While we have gained a lot of insights regarding the effects and mechanism of actions of these promising compounds, further investigations are still warranted in order to design optimal associations of compounds according to the health benefit expected, that is improving weight management, as well as glucose metabolism or even anti-inflammatory properties.

Acknowledgements PDC is a senior research associate at FRS-FNRS (Fonds de la Recherche Scientifique). PDC is a recipient of grants from FNRS, FRFS-WELBIO, under grant: WELBIO-CR-2017-C02, The Excellence Of Science (EOS 30770923), and the Funds Baillet Latour (Grant for Medical Research 2015).

\section{Compliance with Ethical Standards}

Conflict of Interest Matthias Van Hul declares that he has no conflict of interest.

Patrice D. Cani is an inventor listed on patent applications dealing with the use of A. muciniphila and its components to treat obesity and related disorders, and is also co-founder of A-Mansia biotech SA.

Human and Animal Rights and Informed Consent This article does not contain any studies with human or animal subjects performed by any of the authors.

Open Access This article is distributed under the terms of the Creative Commons Attribution 4.0 International License (http:// creativecommons.org/licenses/by/4.0/), which permits unrestricted use, distribution, and reproduction in any medium, provided you give appropriate credit to the original author(s) and the source, provide a link to the Creative Commons license, and indicate if changes were made.

\section{References}

Papers of particular interest, published recently, have been highlighted as:

- Of importance

•• Of major importance

1. NCD Risk Factor Collaboration (NCD-RisC). Worldwide trends in body-mass index, underweight, overweight, and obesity from 1975 to 2016: a pooled analysis of 2416 population-based measurement studies in 128.9 million children, adolescents, and adults. Lancet. 2017;390(10113):2627-42. https://doi.org/10. 1016/S0140-6736(17)32129-3.

2. Ng M, Fleming T, Robinson M, Thomson B, Graetz N, Margono C, et al. Global, regional, and national prevalence of overweight and obesity in children and adults during 1980-2013: a systematic analysis for the global burden of disease study 2013. Lancet. 2014;384(9945): 766-81. https://doi.org/10.1016/S0140-6736(14)60460-8.

3. Masoodi M, Kuda O, Rossmeisl M, Flachs P, Kopecky J. Lipid signaling in adipose tissue: connecting inflammation \& metabolism. Biochim Biophys Acta. 2015;1851(4):503-18. https://doi. org/10.1016/j.bbalip.2014.09.023.

4. Hotamisligil GS. Inflammation and metabolic disorders. Nature. 2006;444(7121):860-7. 
5. Maury E, Brichard SM. Adipokine dysregulation, adipose tissue inflammation and metabolic syndrome. Mol Cell Endocrinol. 2010;314(1):1-16. https://doi.org/10.1016/j.mce.2009.07.031.

6. Cani PD. Human gut microbiome: hopes, threats and promises. Gut. 2018;67(9):1716-25. https://doi.org/10.1136/gutjnl-2018316723 .

7. Turnbaugh PJ, Ley RE, Mahowald MA, Magrini V, Mardis ER, Gordon JI. An obesity-associated gut microbiome with increased capacity for energy harvest. Nature. 2006;444(7122):1027-31.

8. Ley RE, Turnbaugh PJ, Klein S, Gordon JI. Microbial ecology: human gut microbes associated with obesity. Nature. 2006;444(7122):1022-3.

9. Khan MJ, Gerasimidis K, Edwards CA, Shaikh MG. Role of gut microbiota in the aetiology of obesity: proposed mechanisms and review of the literature. J Obes. 2016;2016:7353642. https://doi. org/10.1155/2016/7353642.

10. Knox NC, Forbes JD, Van Domselaar G, Bernstein CN. The gut microbiome as a target for IBD treatment: are we there yet? Curr Treat Options Gastroenterol. 2019;17:115-26. https://doi.org/10. 1007/s11938-019-00221-w.

11. Zuo T, Ng SC. The gut microbiota in the pathogenesis and therapeutics of inflammatory bowel disease. Front Microbiol. 2018;9: 2247. https://doi.org/10.3389/fmicb.2018.02247.

12. Maeda Y, Takeda K. Role of gut microbiota in rheumatoid arthritis. J Clin Med. 2017;6(6). https://doi.org/10.3390/jcm6060060.

13. Lynch SV, Boushey HA. The microbiome and development of allergic disease. Curr Opin Allergy Clin Immunol. 2016;16(2): 165-71. https://doi.org/10.1097/ACI.0000000000000255.

14. Wang Y, Kasper LH. The role of microbiome in central nervous system disorders. Brain Behav Immun. 2014;38:1-12. https://doi. org/10.1016/j.bbi.2013.12.015.

15. Trowell HC. Dietary-fiber hypothesis of the etiology of diabetes mellitus. Diabetes. 1975;24(8):762-5.

16. Jenkins DJ, Goff DV, Leeds AR, Alberti KG, Wolever TM, Gassull MA, et al. Unabsorbable carbohydrates and diabetes: decreased post-prandial hyperglycaemia. Lancet. 1976;2(7978):172-4.

17. Jenkins DJ, Wolever TM, Hockaday TD, Leeds AR, Howarth R, Bacon S, et al. Treatment of diabetes with guar gum. Reduction of urinary glucose loss in diabetics. Lancet. 1977;2(8042):779-80.

18. Jenkins DJ, Wolever TM, Leeds AR, Gassull MA, Haisman P, Dilawari J, et al. Dietary fibres, fibre analogues, and glucose tolerance: importance of viscosity. Br Med J. 1978;1(6124):1392-4.

19. Cani PD, Jordan BF. Gut microbiota-mediated inflammation in obesity: a link with gastrointestinal cancer. Nat Rev Gastroenterol Hepatol. 2018;15(11):671-82. https://doi.org/ 10.1038/s41575-018-0025-6.

20. Louis P, Flint HJ. Formation of propionate and butyrate by the human colonic microbiota. Environ Microbiol. 2017;19(1):29 41. https://doi.org/10.1111/1462-2920.13589.

21. Chambers ES, Preston T, Frost G, Morrison DJ. Role of gut microbiota-generated short-chain fatty acids in metabolic and cardiovascular health. Curr Nutr Rep. 2018;7(4):198-206. https:// doi.org/10.1007/s13668-018-0248-8.

22. Frost G, Sleeth ML, Sahuri-Arisoylu M, Lizarbe B, Cerdan S, Brody L, et al. The short-chain fatty acid acetate reduces appetite via a central homeostatic mechanism. Nat Commun. 2014;5:3611. https://doi.org/10.1038/ncomms4611.

23. Canfora EE, Jocken JW, Blaak EE. Short-chain fatty acids in control of body weight and insulin sensitivity. Nat Rev Endocrinol. 2015;11(10):577-91. https://doi.org/10.1038/nrendo.2015.128.

24. Daubioul CA, Taper HS, De Wispelaere LD, Delzenne NM. Dietary oligofructose lessens hepatic steatosis, but does not prevent hypertriglyceridemia in obese zucker rats. JNutr. 2000;130(5):1314-9.

25. Cani PD, Dewever C, Delzenne NM. Inulin-type fructans modulate gastrointestinal peptides involved in appetite regulation (glucagon-like peptide-1 and ghrelin) in rats. Br J Nutr. 2004;92(3):521-6.

26. Cani PD, Neyrinck AM, Maton N, Delzenne NM. Oligofructose promotes satiety in rats fed a high-fat diet: involvement of glucagon-like peptide-1. Obes Res. 2005;13(6):1000-7.

27. Cani PD, Knauf C, Iglesias MA, Drucker DJ, Delzenne NM, Burcelin R. Improvement of glucose tolerance and hepatic insulin sensitivity by oligofructose requires a functional glucagon-like peptide 1 receptor. Diabetes. 2006;55(5):1484-90.

28. Delzenne NM, Cani PD, Daubioul C, Neyrinck AM. Impact of inulin and oligofructose on gastrointestinal peptides. BrJNutr. 2005;93(Suppl 1):S157-S61.

29. Drucker DJ. Mechanisms of action and therapeutic application of glucagon-like peptide-1. Cell Metab. 2018;27(4):740-56. https:// doi.org/10.1016/j.cmet.2018.03.001.

30. Wang X, Gibson GR. Effects of the in vitro fermentation of oligofructose and inulin by bacteria growing in the human large intestine. J Appl Bacteriol. 1993;75(4):373-80.

31. Aziz AA, Kenney LS, Goulet B, Abdel-Aal E. Dietary starch type affects body weight and glycemic control in freely fed but not energy-restricted obese rats. J Nutr. 2009;139(10):1881-9.

32. Keenan MJ, Zhou J, McCutcheon KL, Raggio AM, Bateman HG, Todd $\mathrm{E}$, et al. Effects of resistant starch, a non-digestible fermentable fiber, on reducing body fat. Obesity(SilverSpring). 2006;14(9):1523-34.

33. Zhou J, Martin RJ, Tulley RT, Raggio AM, McCutcheon KL, Shen L, et al. Dietary resistant starch upregulates total GLP-1 and PYY in a sustained day-long manner through fermentation in rodents. Am J Physiol Endocrinol Metab. 2008;295(5): E1160-E6.

34. Samuel BS, Shaito A, Motoike T, Rey FE, Backhed F, Manchester $\mathrm{JK}$, et al. Effects of the gut microbiota on host adiposity are modulated by the short-chain fatty-acid binding $\mathrm{G}$ protein-coupled receptor, Gpr41. Proc Natl Acad Sci U S A. 2008;105(43):16767-72.

35. Tolhurst G, Heffron H, Lam YS, Parker HE, Habib AM, Diakogiannaki E, et al. Short-chain fatty acids stimulate glucagon-like peptide-1 secretion via the G-protein-coupled receptor FFAR2. Diabetes. 2012;61(2):364-71.

36. Nohr MK, Pedersen MH, Gille A, Egerod KL, Engelstoft MS, Husted AS, et al. GPR41/FFAR3 and GPR43/FFAR2 as cosensors for short-chain fatty acids in enteroendocrine cells vs FFAR3 in enteric neurons and FFAR2 in enteric leukocytes. Endocrinology. 2013;154(10):3552-64. https://doi.org/10.1210/en.2013-1142.

37. Brooks L, Viardot A, Tsakmaki A, Stolarczyk E, Howard JK, Cani PD, et al. Fermentable carbohydrate stimulates FFAR2-dependent colonic PYY cell expansion to increase satiety. Mol Metab. 2017;6(1):48-60. https://doi.org/10.1016/j.molmet.2016.10.011.

38. Psichas A, Sleeth ML, Murphy KG, Brooks L, Bewick GA, Hanyaloglu AC, et al. The short chain fatty acid propionate stimulates GLP-1 and PYY secretion via free fatty acid receptor 2 in rodents. Int J Obes. 2015;39(3):424-9. https://doi.org/10.1038/ijo.2014.153.

39. Koh A, De Vadder F, Kovatcheva-Datchary P, Backhed F. From dietary fiber to host physiology: short-chain fatty acids as key bacterial metabolites. Cell. 2016;165(6):1332-45. https://doi.org/ 10.1016/j.cell.2016.05.041. An excellent review exploring how the gut bacteria are producing SCFAs and how they contribute to host metabolism.

40. Cani PD, Joly E, Horsmans Y, Delzenne NM. Oligofructose promotes satiety in healthy human: a pilot study. Eur J Clin Nutr. 2006;60(5):567-72.

41. Cani PD, Lecourt E, Dewulf EM, Sohet FM, Pachikian BD, Naslain D, et al. Gut microbiota fermentation of prebiotics increases satietogenic and incretin gut peptide production with consequences for appetite sensation and glucose response after a meal. Am J Clin Nutr. 2009;90(5):1236-43. 
42. Parnell JA, Reimer RA. Weight loss during oligofructose supplementation is associated with decreased ghrelin and increased peptide YY in overweight and obese adults. Am J Clin Nutr. 2009;89(6):1751-9.

43. Peters HP, Boers HM, Haddeman E, Melnikov SM, Qvyjt F. No effect of added beta-glucan or of fructooligosaccharide on appetite or energy intake. Am J Clin Nutr. 2009;89(1):58-63.

44. Tarini J, Wolever TM. The fermentable fibre inulin increases postprandial serum short-chain fatty acids and reduces free-fatty acids and ghrelin in healthy subjects. Appl Physiol Nutr Metab. 2010;35(1):9-16.

45. Klosterbuer AS, Thomas W, Slavin JL. Resistant starch and pullulan reduce postprandial glucose, insulin, and GLP-1, but have no effect on satiety in healthy humans. J Agric Food Chem. 2012;60(48):11928-34. https://doi.org/10.1021/jf303083r.

46. Frost G, Brynes A, Leeds A. Effect of large bowel fermentation on insulin, glucose, free fatty acids, and glucagon-like peptide 1 (736) amide in patients with coronary heart disease. Nutrition. 1999;15(3):183-8.

47. Bird AR, Conlon MA, Christophersen CT, Topping DL. Resistant starch, large bowel fermentation and a broader perspective of prebiotics and probiotics. Benefic Microbes. 2010;1(4):423-31. https://doi.org/10.3920/BM2010.0041.

48. Robertson MD. Dietary-resistant starch and glucose metabolism. Curr Opin Clin Nutr Metab Care. 2012;15(4):362-7. https://doi. org/10.1097/MCO.0b013e3283536931.

49. Nilsson A, Johansson E, Ekstrom L, Bjorck I. Effects of a brown beans evening meal on metabolic risk markers and appetite regulating hormones at a subsequent standardized breakfast: a randomized cross-over study. PLoS One. 2013;8(4):e59985. https://doi. org/10.1371/journal.pone.0059985.

50. Daud NM, Ismail NA, Thomas EL, Fitzpatrick JA, Bell JD, Swann JR, et al. The impact of oligofructose on stimulation of gut hormones, appetite regulation and adiposity. Obesity (Silver Spring). 2014;22(6):1430-8. https://doi.org/10.1002/oby.20754.

51. Korczak R, Slavin JL. Fructooligosaccharides and appetite. Curr Opin Clin Nutr Metab Care. 2018;21(5):377-80. https://doi.org/ 10.1097/MCO.0000000000000502.

$52 . \bullet$ Zhao L, Zhang F, Ding X, Wu G, Lam YY, Wang X, et al. Gut bacteria selectively promoted by dietary fibers alleviate type 2 diabetes. Science. 2018;359(6380):1151-6. https://doi.org/10. 1126/science.aao5774. An outstanding example of investigation in humans showing how the modification of the source of carbohydrates and polyphenols can positively affect the host metabolism and their link with both the gut microbiota composition and the metabolites produced.

53. Gibson GR, Roberfroid MB. Dietary modulation of the human colonic microbiota: introducing the concept of prebiotics. J Nutr. 1995;125(6):1401-12. https://doi.org/10.1093/jn/125.6.1401.

54. Carlson JL, Erickson JM, Lloyd BB, Slavin JL. Health effects and sources of prebiotic dietary fiber. Curr Dev Nutr. 2018;2(3): nzy005. https://doi.org/10.1093/cdn/nzy005.

55.• Gibson GR, Hutkins R, Sanders ME, Prescott SL, Reimer RA, Salminen SJ, et al. Expert consensus document: The International Scientific Association for Probiotics and Prebiotics (ISAPP) consensus statement on the definition and scope of prebiotics. Nat Rev Gastroenterol Hepatol. 2017;14(8):491-502. https://doi.org/ 10.1038/nrgastro.2017.75. In this statement, a panel of experts discuss the term and scope of "prebiotics" in order to define a consensus characterisation that is uniformly applicable in research, marketing and regulation. They also review several aspects of prebiotic science including its development, health benefits and legislation.

56. Tsao R. Chemistry and biochemistry of dietary polyphenols. Nutrients. 2010;2(12):1231-46. https://doi.org/10.3390/ nu2121231.
57. Neveu V, Perez-Jimenez J, Vos F, Crespy V, du Chaffaut L, Mennen L, et al. Phenol-explorer: an online comprehensive database on polyphenol contents in foods. Database (Oxford). 2010;2010:bap024. https://doi.org/10.1093/database/bap024.

58. Cory H, Passarelli S, Szeto J, Tamez M, Mattei J. The role of polyphenols in human health and food systems: a mini-review. Front Nutr. 2018;5:87. https://doi.org/10.3389/fnut.2018.00087.

59. Singh A, Holvoet S, Mercenier A. Dietary polyphenols in the prevention and treatment of allergic diseases. Clin Exp Allergy. 2011;41(10):1346-59. https://doi.org/10.1111/j. 1365-2222.2011.03773.x.

60. Wang S, Moustaid-Moussa N, Chen L, Mo H, Shastri A, Su R, et al. Novel insights of dietary polyphenols and obesity. J Nutr Biochem. 2014;25(1):1-18. https://doi.org/10.1016/j.jnutbio. 2013.09.001.

61. Yang CS, Zhang J, Zhang L, Huang J, Wang Y. Mechanisms of body weight reduction and metabolic syndrome alleviation by tea. Mol Nutr Food Res. 2016;60(1):160-74. https://doi.org/10.1002/ mnfr.201500428. In this publication, Yang et al introduce their so-called "AMPK hypothesis" in which polyphenols are suggested to activate AMP-activated protein kinase (AMPK) by phosphorylation, thereby modulating some proteins involved in adipogenesis, lipogenesis, and lipolysis.

62. Hiroki T, Monira P, Shingo G, Mamoru I, Yoriyuki N. Beneficial effects of plant polyphenols on obesity. Obes Control Ther. 2017;4(3):1-16. https://doi.org/10.15226/2374-8354/4/3/00142.

63. Meydani M, Hasan ST. Dietary polyphenols and obesity. Nutrients. 2010;2(7):737-51. https://doi.org/10.3390/nu2070737.

64. Springer M, Moco S. Resveratrol and its human metaboliteseffects on metabolic health and obesity. Nutrients. 2019;11(1). https://doi.org/10.3390/nu11010143.

65. Chiva-Blanch G, Badimon L. Effects of polyphenol intake on metabolic syndrome: current evidences from human trials. Oxidative Med Cell Longev. 2017;2017:5812401. https://doi. org/10.1155/2017/5812401. Overview of the human interventional trials investigating the effects of polyphenols in patients with metabolic syndrome, suggesting that the protective effects of polyphenols may be reached through a long-term regular, daily consumption.

66. Guo X, Tresserra-Rimbau A, Estruch R, Martínez-González MA, Medina-Remón A, Fitó M, Corella D, et al. Polyphenol levels are inversely correlated with body weight and obesity in an elderly population after 5 years of follow up (The Randomised PREDIMED Study). Nutrients. 2017;9(5): E452. https://doi.org/10.3390/nu9050452.

67. Rothenberg DO, Zhou C, Zhang L. A review on the weight-loss effects of oxidized tea polyphenols. Molecules. 2018;23(5): E1176. https://doi.org/10.3390/molecules23051176.

68. Vazquez Cisneros LC, Lopez-Uriarte P, Lopez-Espinoza A, Navarro Meza M, Espinoza-Gallardo AC, Guzman Aburto MB. Effects of green tea and its epigallocatechin (EGCG) content on body weight and fat mass in humans: a systematic review. Nutr Hosp. 2017;34(3):731-7. https://doi.org/10.20960/nh.753.

69. Rains TM, Agarwal S, Maki KC. Antiobesity effects of green tea catechins: a mechanistic review. J Nutr Biochem. 2011;22(1):1-7. https://doi.org/10.1016/j.jnutbio.2010.06.006.

70. Miyatake N, Sakano N, Numata T. Comparison of coffee, tea and green tea consumption between Japanese with and without metabolic syndrome in a cross-sectional study. Open J Epidemiol. 2012;2:44-9. https://doi.org/10.4236/ojepi.2012.22007.

71. Zhang B, Deng Z, Ramdath DD, Tang Y, Chen PX, Liu R, et al. Phenolic profiles of 20 Canadian lentil cultivars and their contribution to antioxidant activity and inhibitory effects on alphaglucosidase and pancreatic lipase. Food Chem. 2015;172:86272. https://doi.org/10.1016/j.foodchem.2014.09.144. 
72. Yamagata K, Tagami M, Yamori Y. Dietary polyphenols regulate endothelial function and prevent cardiovascular disease. Nutrition. 2015;31(1):28-37. https://doi.org/10.1016/j.nut.2014.04.011.

73. Xiao JB, Hogger P. Dietary polyphenols and type 2 diabetes: current insights and future perspectives. Curr Med Chem. 2015;22(1):23-38.

74. Wang S, Sun Z, Dong S, Liu Y, Liu Y. Molecular interactions between (-)-epigallocatechin gallate analogs and pancreatic lipase. PLoS One. 2014;9(11):e111143. https://doi.org/10.1371/ journal.pone.0111143.

75. Jakobek L. Interactions of polyphenols with carbohydrates, lipids and proteins. Food Chem. 2015;175:556-67. https://doi.org/10. 1016/j.foodchem.2014.12.013.

76. Barrett AH, Farhadi NF, Smith TJ. Slowing starch digestion and inhibiting digestive enzyme activity using plant flavanols/tannins - a review of efficacy and mechanisms. LWT. 2018;87: 394-9. https://doi.org/10.1016/j.lwt.2017.09.002.

77. Huang J, Wang Y, Xie Z, Zhou Y, Zhang Y, Wan X. The antiobesity effects of green tea in human intervention and basic molecular studies. Eur J Clin Nutr. 2014;68(10):1075-87. https://doi. org/10.1038/ejen.2014.143.

78. Pan MH, Tung YC, Yang G, Li S, Ho CT. Molecular mechanisms of the anti-obesity effect of bioactive compounds in tea and coffee. Food Funct. 2016;7(11):4481-91. https://doi.org/10.1039/ c6fo01168c.

79. Rocha A, Bolin AP, Cardoso CA, Otton R. Green tea extract activates AMPK and ameliorates white adipose tissue metabolic dysfunction induced by obesity. Eur J Nutr. 2016;55(7):2231-44. https://doi.org/10.1007/s00394-015-1033-8.

80. Garcia D, Shaw RJ. AMPK: mechanisms of cellular energy sensing and restoration of metabolic balance. Mol Cell. 2017;66(6): 789-800. https://doi.org/10.1016/j.molcel.2017.05.032.

81. Yang CS, Wang H, Sheridan ZP. Studies on prevention of obesity, metabolic syndrome, diabetes, cardiovascular diseases and cancer by tea. J Food Drug Anal. 2018;26(1):1-13. https://doi.org/10. 1016/j.jfda.2017.10.010.

82. Williamson G, Manach C. Bioavailability and bioefficacy of polyphenols in humans. II. Review of 93 intervention studies. Am J Clin Nutr. 2005;81(1 Suppl):243S-55S. https://doi.org/ 10.1093/ajen/81.1.243S.

83. Hervert-Hernandez D, Pintado C, Rotger R, Goni I. Stimulatory role of grape pomace polyphenols on Lactobacillus acidophilus growth. Int J Food Microbiol. 2009;136(1):119-22. https://doi. org/10.1016/j.ijfoodmicro.2009.09.016.

84. Masumoto S, Terao A, Yamamoto Y, Mukai T, Miura T, Shoji T. Non-absorbable apple procyanidins prevent obesity associated with gut microbial and metabolomic changes. Sci Rep. 2016;6: 31208. https://doi.org/10.1038/srep31208.

85. Roopchand DE, Carmody RN, Kuhn P, Moskal K, Rojas-Silva P, Turnbaugh PJ, et al. Dietary polyphenols promote growth of the gut bacterium Akkermansia muciniphila and attenuate high-fat diet-induced metabolic syndrome. Diabetes. 2015;64(8):284758. https://doi.org/10.2337/db14-1916.

86. Cardona F, Andres-Lacueva C, Tulipani S, Tinahones FJ, QueipoOrtuno MI. Benefits of polyphenols on gut microbiota and implications in human health. J Nutr Biochem. 2013;24(8):1415-22. https://doi.org/10.1016/j.jnutbio.2013.05.001.

87. Duda-Chodak A, Tarko T, Satora P, Sroka P. Interaction of dietary compounds, especially polyphenols, with the intestinal microbiota: a review. Eur J Nutr. 2015;54(3):325-41. https://doi.org/10. 1007/s00394-015-0852-y.

88. Etxeberria U, Fernandez-Quintela A, Milagro FI, Aguirre L, Martinez JA, Portillo MP. Impact of polyphenols and polyphenolrich dietary sources on gut microbiota composition. J Agric Food Chem. 2013;61(40):9517-33. https://doi.org/10.1021/jf402506c.

89. Marin L, Miguelez EM, Villar CJ, Lombo F. Bioavailability of dietary polyphenols and gut microbiota metabolism: antimicrobial properties. Biomed Res Int. 2015;2015:905215. https://doi.org/10. 1155/2015/905215.

90. Bialonska D, Ramnani P, Kasimsetty SG, Muntha KR, Gibson GR, Ferreira D. The influence of pomegranate by-product and punicalagins on selected groups of human intestinal microbiota. Int J Food Microbiol. 2010;140(2-3):175-82. https://doi.org/10. 1016/j.ijfoodmicro.2010.03.038.

91. Tuohy KM, Conterno L, Gasperotti M, Viola R. Up-regulating the human intestinal microbiome using whole plant foods, polyphenols, and/or fiber. J Agric Food Chem. 2012;60(36):8776-82. https://doi.org/10.1021/jf2053959.

92. Bustos I, Garcia-Cayuela T, Hernandez-Ledesma B, Pelaez C, Requena T, Martinez-Cuesta MC. Effect of flavan-3-ols on the adhesion of potential probiotic lactobacilli to intestinal cells. J Agric Food Chem. 2012;60(36):9082-8. https://doi.org/10.1021/jf301133g.

93. Celebioglu HU, Svensson B. Dietary nutrients, proteomes, and adhesion of probiotic lactobacilli to mucin and host epithelial cells. Microorganisms. 2018;6(3):E90. https://doi.org/10.3390/ microorganisms6030090.

94. Kailasapathy K, Chin J. Survival and therapeutic potential of probiotic organisms with reference to Lactobacillus acidophilus and Bifidobacterium spp. Immunol Cell Biol. 2000;78(1):80-8. https://doi.org/10.1046/j.1440-1711.2000.00886.x.

95. Kawabata K, Yoshioka Y, Terao J. Role of intestinal microbiota in the bioavailability and physiological functions of dietary polyphenols. Molecules. 2019;24(2). https://doi.org/10.3390/ molecules 24020370 .

96. Luca SV, Macovei I, Bujor A, Miron A, Skalicka-Wozniak K, Aprotosoaie AC, et al. Bioactivity of dietary polyphenols: the role of metabolites. Crit Rev Food Sci Nutr. 2019:1-34. https://doi.org/ 10.1080/10408398.2018.1546669.

97. Del Rio D, Rodriguez-Mateos A, Spencer JP, Tognolini M, Borges G, Crozier A. Dietary (poly)phenolics in human health: structures, bioavailability, and evidence of protective effects against chronic diseases. Antioxid Redox Signal. 2013;18(14):1818-92. https:// doi.org/10.1089/ars.2012.4581.

98. Filosa S, Di Meo F, Crispi S. Polyphenols-gut microbiota interplay and brain neuromodulation. Neural Regen Res. 2018;13(12): 2055-9. https://doi.org/10.4103/1673-5374.241429.

99. Ozdal T, Sela DA, Xiao J, Boyacioglu D, Chen F, Capanoglu E. The reciprocal interactions between polyphenols and gut microbiota and effects on bioaccessibility. Nutrients. 2016;8(2):78. https:// doi.org/10.3390/nu8020078. Review summarizing how polyphenols are metabolized by the gut microbiota and how the gut microbiota is modulated by polyphenols.

100. Russell W, Duthie G. Plant secondary metabolites and gut health: the case for phenolic acids. Proc Nutr Soc. 2011;70(3):389-96. https://doi.org/10.1017/S0029665111000152.

101. Aprikian O, Duclos V, Guyot S, Besson C, Manach C, Bernalier $\mathrm{A}$, et al. Apple pectin and a polyphenol-rich apple concentrate are more effective together than separately on cecal fermentations and plasma lipids in rats. J Nutr. 2003;133(6):1860-5. https://doi.org/ 10.1093/jn/133.6.1860.

102. Zdunczyk Z, Juskiewicz J, Estrella I. Cecal parameters of rats fed diets containing grapefruit polyphenols and inulin as single supplements or in a combination. Nutrition. 2006;22(9):898-904. https://doi.org/10.1016/j.nut.2006.05.010.

103. Sadeghi Ekbatan S, Sleno L, Sabally K, Khairallah J, Azadi B, Rodes L, et al. Biotransformation of polyphenols in a dynamic multistage gastrointestinal model. Food Chem. 2016;204:45362. https://doi.org/10.1016/j.foodchem.2016.02.140.

104. Fotschki B, Juskiewicz J, Jurgonski A, Kolodziejczyk K, Milala J, Kosmala M, et al. Anthocyanins in strawberry polyphenolic extract enhance the beneficial effects of diets with fructooligosaccharides in the rat cecal environment. PLoS One. 2016;11(2): e0149081. https://doi.org/10.1371/journal.pone.0149081. 
105. Kawabata K, Kato Y, Sakano T, Baba N, Hagiwara K, Tamura A, et al. Effects of phytochemicals on in vitro anti-inflammatory activity of Bifidobacterium adolescentis. Biosci Biotechnol Biochem. 2015;79(5):799-807. https://doi.org/10.1080/ 09168451.2015 .1006566$.

106. Bialonska D, Kasimsetty SG, Schrader KK, Ferreira D. The effect of pomegranate (Punica granatum L.) byproducts and ellagitannins on the growth of human gut bacteria. J Agric Food Chem. 2009;57(18):8344-9. https://doi.org/10.1021/j9901931b.

107. Puupponen-Pimia R, Nohynek L, Hartmann-Schmidlin S, Kahkonen M, Heinonen M, Maatta-Riihinen K, et al. Berry phenolics selectively inhibit the growth of intestinal pathogens. J Appl Microbiol. 2005;98(4):991-1000. https://doi.org/10.1111/j. 1365-2672.2005.02547.x.

108. Taguri T, Tanaka T, Kouno I. Antimicrobial activity of 10 different plant polyphenols against bacteria causing food-borne disease. Biol Pharm Bull. 2004;27(12):1965-9.

109. Espin JC, Gonzalez-Sarrias A, Tomas-Barberan FA. The gut microbiota: a key factor in the therapeutic effects of (poly)phenols. Biochem Pharmacol. 2017;139:82-93. https://doi.org/10.1016/j. bcp.2017.04.033.

110. Van Hul M, Geurts L, Plovier H, Druart C, Everard A, Stahlman M, et al. Reduced obesity, diabetes, and steatosis upon cinnamon and grape pomace are associated with changes in gut microbiota and markers of gut barrier. Am J Physiol Endocrinol Metab. 2018;314(4):E334-E52. https://doi.org/10.1152/ajpendo.00107.2017.

111. Anhe FF, Roy D, Pilon G, Dudonne S, Matamoros S, Varin TV, et al. A polyphenol-rich cranberry extract protects from dietinduced obesity, insulin resistance and intestinal inflammation in association with increased Akkermansia spp. population in the gut microbiota of mice. Gut. 2015;64(6):872-83. https://doi.org/10. 1136/gutjnl-2014-307142.

112.• Anhê FF, Nachbar RT, Varin TV, Trot tier J, Dudonné S, Le Barz M, et al. Treatment with camu camu (Myrciaria dubia) prevents obesity by altering the gut microbiota and increasing energy expenditure in diet-induced obese mice. Gut. 2018;68:453-64:gutjnl-2017315565. https://doi.org/10.1136/gutjnl-2017-315565. Key example of a study in mice that shows how polyphenols (an extract from Camu camu in this case) causally prevent obesity and metabolic disease and exert its positive effects, at least in part, through the modulation of the gut microbiota (here: a blooming of $A$. muciniphila and a significant reduction in Lactobacillus bacteria).

113. Jiao X, Wang Y, Lin Y, Lang Y, Li E, Zhang X, et al. Blueberry polyphenols extract as a potential prebiotic with anti-obesity effects on C57BL/6 J mice by modulating the gut microbiota. J Nutr Biochem. 2019;64:88-100. https://doi.org/10.1016/j.jnutbio.2018.07.008.

114. Wang P, Li D, Ke W, Liang D, Hu X, Chen F. Resveratrol-induced gut microbiota reduces obesity in high-fat diet-fed mice. Int J Obes (Lond). 2019. https://doi.org/10.1038/s41366-019-0332-1.

115. Janssens PL, Penders J, Hursel R, Budding AE, Savelkoul PH, Westerterp-Plantenga MS. Long-term green tea supplementation does not change the human gut microbiota. PLoS One. 2016;11(4): e0153134. https://doi.org/10.1371/journal.pone.0153134.

116. Cani PD, de Vos WM. Next-generation beneficial microbes: the case of Akkermansia muciniphila. Front Microbiol. 2017;8:1765. https://doi.org/10.3389/fmicb.2017.01765.

117. Everard A, Belzer C, Geurts L, Ouwerkerk JP, Druart C, Bindels LB, et al. Cross-talk between Akkermansia muciniphila and intestinal epithelium controls diet-induced obesity. PNAS United States of America. 2013;110(22):9066-71. https://doi.org/10. 1073/pnas.1219451110.

118. Plovier H, Cani PD. Microbial impact on host metabolism: opportunities for novel treatments of nutritional disorders? Microbiol Spectr. 2017;5(3):1-13. https://doi.org/10.1128/microbiolspec. BAD-0002-2016.
119. Pierre JF, Heneghan AF, Feliciano RP, Shanmuganayagam D, Roenneburg DA, Krueger CG, et al. Cranberry proanthocyanidins improve the gut mucous layer morphology and function in mice receiving elemental enteral nutrition. JPEN J Parenter Enteral Nutr. 2013;37(3):401-9. https://doi.org/10.1177/0148607112463076.

120. Baldwin J, Collins B, Wolf PG, Martinez K, Shen W, Chuang CC, et al. Table grape consumption reduces adiposity and markers of hepatic lipogenesis and alters gut microbiota in butter fat-fed mice. J Nutr Biochem. 2016;27:123-35. https://doi.org/10.1016/j. jnutbio.2015.08.027.

121. Anhe FF, Pilon G, Roy D, Desjardins Y, Levy E, Marette A. Triggering Akkermansia with dietary polyphenols: a new weapon to combat the metabolic syndrome? Gut Microbes. 2016;7(2): 146-53. https://doi.org/10.1080/19490976.2016.1142036.

122. Etxeberria U, Arias N, Boque N, Macarulla MT, Portillo MP, Martinez JA, et al. Reshaping faecal gut microbiota composition by the intake of trans-resveratrol and quercetin in high-fat sucrose diet-fed rats. J Nutr Biochem. 2015;26(6):651-60. https://doi.org/ 10.1016/j.jnutbio.2015.01.002.

123. Li Z, Henning SM, Lee RP, Lu QY, Summanen PH, Thames G, et al. Pomegranate extract induces ellagitannin metabolite formation and changes stool microbiota in healthy volunteers. Food Funct. 2015;6(8):2487-95. https://doi.org/10.1039/c5fo00669d.

124. Anhe FF, Varin TV, Le Barz M, Pilon G, Dudonne S, Trottier J, et al. Arctic berry extracts target the gut-liver axis to alleviate metabolic endotoxaemia, insulin resistance and hepatic steatosis in diet-induced obese mice. Diabetologia. 2018;61(4):919-31. https://doi.org/10.1007/s00125-017-4520-z.

125. Renard CMGC, Watrelot AA, Le Bourvellec C. Interactions between polyphenols and polysaccharides: mechanisms and consequences in food processing and digestion. Trends Food Sci Technol. 2017;60:43-51. https://doi.org/10.1016/j.tifs.2016.10.022.

126. Edwards CA, Havlik J, Cong W, Mullen W, Preston T, Morrison DJ, et al. Polyphenols and health: interactions between fibre, plant polyphenols and the gut microbiota. Nutr Bull. 2017;42(4):35660. https://doi.org/10.1111/nbu.12296.

127. Crowe KM, Francis C. Academy of N, Dietetics. Position of the academy of nutrition and dietetics: functional foods. $\mathrm{J}$ Acad Nutr Diet. 2013;113(8):1096-103. https://doi.org/10. 1016/j.jand.2013.06.002.

128. Williamson G, Holst B. Dietary reference intake (DRI) value for dietary polyphenols: are we heading in the right direction? Br J Nutr. 2008;99(Supp1 3):S55-8. https://doi.org/10.1017/ S0007114508006867.

129. Murase T, Haramizu S, Shimotoyodome A, Tokimitsu I. Reduction of diet-induced obesity by a combination of teacatechin intake and regular swimming. Int J Obes. 2006;30(3): 561-8. https://doi.org/10.1038/sj.ijo.0803135.

130. Shimotoyodome A, Haramizu S, Inaba M, Murase T, Tokimitsu I. Exercise and green tea extract stimulate fat oxidation and prevent obesity in mice. Med Sci Sports Exerc. 2005;37(11):1884-92.

131. Lorenz M, Paul F, Moobed M, Baumann G, Zimmermann BF, Stangl K, et al. The activity of catechol-O-methyltransferase (COMT) is not impaired by high doses of epigallocatechin-3gallate (EGCG) in vivo. Eur J Pharmacol. 2014;740:645-51. https://doi.org/10.1016/j.ejphar.2014.06.014.

Publisher's Note Springer Nature remains neutral with regard to jurisdictional claims in published maps and institutional affiliations. 